\title{
Top-Down and Outside-In: Breaking Boundaries between Research, Theory and Practice in Education
}

\author{
Daniel Gregson \\ University of Sunderland \\ Maggie Gregson \\ University of Sunderland \\ Trish Spedding \\ University of Sunderland
}

This article challenges divisions which have been set up between practice, research and theory in relation to the discipline of Education. It questions the epistemic positions upon which positivist metanarratives underpinning these divisions are founded. These include the separation of practice from research and theory and the creation of the notion of a vocational and academic divide. We provide insights into how a University-supported, practitioner-research programme (PRP), which draws upon Dewey's pragmatic epistemology, is impacting upon the improvement of educational practice, processes of educational inquiry and the development of theory in the Further Adult and Vocational Education (FAVE) sector in England.

Keywords: Practice-focused Research, Further Adult and Vocational Education, Practitioner-research, Educational Evaluation and Improvement, Stories

\section{PROBLEM AND CONTEXT}

Over the past 30 years, there has been a rise in metanarratives surrounding the discipline and practice of Education which claim that 'scientific methods', based upon positivist epistemology, are the only way that research can and should be conducted. From this perspective, direct experience and practitionerresearch are not valued and are not to be trusted. To compound the problem, in many countries, neoliberal views of education have taken over the political discourse, by publicly and enthusiastically embracing the values and language of the market. This discourse includes calls for ever greater, 'privatization', 'competition' and 'freedom of choice', for parents and students who are framed as the customers or consumers of education. The language of the market and its accompanying metrics currently dominate the landscape of education in England. What is now valued is what can be easily measured. An important consequence of this is that the measurement of teachers' performance, including what counts as quality in 
education are now evaluated through narrowly framed national inspection criteria and international league tables (Arnove et. al., 1996, Coffield 2008, 2017, Ball 2008, 2018).

Supporters of positivist metanarratives argue that 'big research', randomized control trials and metaanalyses which lead to the production of effect sizes, league tables etc. are the only forms of research which produce authentic knowledge. Practitioner-research is publicly and often stridently condemned as being simply "not good enough". Some (but not all) of this criticism is justified. It is not difficult to find examples of poorly conducted practitioner-research. However, it is equally easy to find examples of major, high profile research studies, influenced by positivistic epistemology which claim to be 'precise and scientific' but involve the use of blunt research instruments and crude measures with, 'large samples smoothing out errors and disguising instances of significant success or failure' (Gardner et. al., 2008, p. 89).

From a slightly different perspective, representatives from universities and other institutions of Higher Education (HE) are also critical of practitioner-research. They argue that they are specialists in educational research and only they understand research methodologies and methods well enough to put them to work effectively and to report them clearly enough to be able to disseminate rigorous and robust findings of research studies to wider audiences. The main thrust of this argument is that practitionerresearch is not systematic or 'scientific' enough to produce rigorous, robust, original or significant research outcomes.

In contrast, others (including ourselves) take the view that practitioner-research matters as much if not more than research based on randomized control trials, meta analyses and research conducted in HE, because practitioner research is uniquely capable of taking context and local knowledge seriously. Following Kemmis (1995) and Carr (1995) we argue that practice is the arena where ideas from other types of research and theories generated by those in HE and elsewhere are tested and challenged.

In the heat and noise of debates about what counts as educational research, the focus has been largely upon "what works" rather than upon what research in education is for - its purposes and its values. We question the dichotomies constructed by positivist metanarratives. We challenge the divisions set up by such narratives. In particular we contest divisions set up between practice, theory and research in relation to educational research conducted in the pursuit of educational improvement. We also cast doubt upon the legitimacy of historical, social and cultural constructions of a vocational-academic divide.

The practice of Education we argue is a moral activity and should always be about doing the right thing for individuals and groups of learners in context, in the light of local knowledge and in view of experience. This is a very different proposition to one which advocates that the role of teachers is simply to apply ideas developed by others in other contexts who then proclaim themselves to be the possessors of absolute truths about "what works".

Acting in the interests of educational values and the public good is a very different activity to one which is driven by the values and dubious morals of the market in which teachers are held in positions of low status and low trust. Coffield (2008) points to how the view of education as a market has led to a growing body of literature promoting 'quality' systems requiring the micro-management of teachers which advocate approaches to improving educational practice from the 'top-down' and from the 'outsidein'. It is worth pausing here to note how little of the literature in praise of the virtues of 'top-down', 'outside-in' approaches to educational improvement has been written by teachers, the very people who are held directly responsible and accountable for the improvement of educational practice.

Coffield (2017) expresses serious reservations about approaches to educational evaluation and inspection in England which assume that the complexity and quality of education can be reduced to a number between 1 and 4 , where 1 is considered to be 'outstanding' and 4 signals an imperative to 'improve'. Ball $(2008,2018)$ draws attention to how this 'top-down' and 'outside-in' system of education in England has spawned a culture of 'terror' and 'performativity' where educational outcomes are fabricated for the purposes of securing a publicly applauded outcome in a high stakes inspection regime. In England, approaches to educational improvement which encourage this kind of gaming are proving to be of limited value to politicians, policy professionals, taxpayers, parents and learners alike. Coffield $(2008,2014,2017)$ and Gregson and Nixon (2008) note that, despite unprecedented levels of public 
investment in educational improvement in England it is difficult to discern any commensurate increase in the quality of results. For example, as Coffield (2017, pp. 7-8) observes, 'the puzzle that remains is why Ofsted's ratings improve year on year, but the scores of English students on international tests such as the Programme for International Studies Assessment (PISA) decline'.

\section{LITERATURE REVIEW}

This literature review, in this section of the article, is presented in two parts. The first focuses upon philosophical issues surrounding the separation of practice from research and theory. The second presents a challenge to the social, cultural, historical and political construction of the notion of a vocationalacademic divide.

\section{CHALLENGING THE THEORY-PRACTICE DIVIDE}

We indicate above, how Educational research in England is often characterized by researchers from institutions of HE presenting their accounts of the educational practice of teachers. We also note how public reports produced by external inspection bodies in England, for example, the Office for Standards in Education (Ofsted) in the form of evaluative reports are made publicly available for the "naming and shaming' of those practitioners and institutions considered to be underperforming. We also observe that while the improvement and development of educational practice is a political and policy priority across all phases and fields of education, teachers often regard educational research as foreign territory, open only to the activities of a privileged elite of research specialists from institutions of HE. This has tended to encourage teachers to see educational research as being far removed from educational practice. In effect, as an elitist pursuit in which systematic, rigorous and robust research design can only be determined in advance by a prescient and privileged few, in situations where research always proceeds in expected and unproblematic ways. Not surprisingly, this view of educational research actively discourages most teachers from engaging in it!

In addition, of the few teachers who do engage in educational research, many do so with a great deal of trepidation and considerable lack of confidence. Often this means that they do not see their research through to completion, let alone to peer-review and publication stage. As a consequence, much practitioner-research does not have a discernible impact upon practice. Ironically, a great deal of educational research conducted by researchers from HE is never read by a wider audience and therefore does not have much impact upon practice either. These are some of the reasons why the positivist, technical-rational metanarrative of educational improvement from the 'top-down' and the 'outside in' 'fails.

This article explores how teachers' confidence and willingness to engage in, educational research might be encouraged through programmes of University-supported, practitioner-research. The Practitioner Research Programme which forms the focus of this study (PRP) is funded and provided in a partnership between the University of Sunderland and the Education and Training Foundation (ETF), the representative body in England for the Further Adult and Vocational Education (FAVE) sector.

The PRP begins with the practice-focused concerns of teachers and uses direct experience, inquiry into practice, story, and other creative media to develop understandings of key ideas, theories and concepts in educational research and practice. These include considerations of the realities of conducting educational research: recognizing and knowing what your research has found; the processes of educational inquiry; the processes involved in the improvement of practice; and the processes involved in the development of high standards of research and scholarship expected in the academy.

To say that the only way to conduct educational research is through rigorous laboratory methods and randomized control trials, is to deny the importance of local knowledge and context. It is also to overlook the role of practitioner judgement in the improvement of educational practice. To try to reduce educational research to a list of repeatable "teacher proof" experiments that can be routinely replicated from London to Illinois, is to see the world in a particularly narrow and technical way in which human 
experience plays little or no part. To see the world in this way is to remove us from the stories we tell ourselves about ourselves and the world we live in. The world of education is no different to any other world, including the world of Art, Engineering, Drama, Maths and Science. We need stories to help us to make sense of all of these practices, all of these forms of life and the ways in which we can come to know them (Eisner, 1993).

In the Predictable Failure of Educational Reform, Sarason (1990), argues that the practice of education is routinely formed and transformed, not by its outsiders, but by its insiders. Those who care about education enough to spend their lives engaged in pursuit of the improvement of its practice (Dunne, 2005). Those who worry about the consequences of that practice enough to keep trying to get better at it, sometimes by making small incremental improvements, sometimes via more radical leaps and bounds. From this point of view, the capacities of teachers to conduct research into their own practice in order to improve it, is a crucial engine of progress. Their ability to share and learn from their own experiences of education and the experiences of others, both face-to-face and through written and oral stories, is a motor that drives progress forward on a wider scale.

This is not to take the position that teachers cannot and should not learn from the research of others. It is to say however, that they may be able to learn and engage more deeply with ideas from the research of others when that research is presented in ways which are connected to practical experience in the form of 'stories' told by other teachers and other researchers and scholars who have tried to understand the world in general, and the world of education in particular, before them. These stories of practical experiences of education, research, theory development and scholarship underpin the pedagogical interventions employed the PRP.

\section{ATTEMPTING TO LOOSEN THE GRIP OF THE VOCATIONAL ACADEMIC DIVIDE IN ENGLAND}

The existence of a vocational-academic divide is often used to justify the second-class status of vocational education in relation to academic education. Hyland (2017) identifies the historical construction of a divide between vocational and academic education and the introduction of the notion of a differential hierarchy in educational pursuits which separates the theoretical from the practical and the social stratification of mental activities above physical activities. He locates the construction of this divide in the class systems of Ancient Greece, where the inferior status of the vocational, positioned it as being unworthy of the elite. Hyland (2019) argues, that for centuries, this has reinforced the notion that only cognitive aspects of learning are of interest and of value in education. This partial and misguided conception he argues, contributes to this day to the subordinate and second-class status of vocational education.

Gregson and Todd (2018) point to how the term vocational continues to carry second-rate connotations in England, in a culture where 'academic' and 'professional' education are prized above an education for the purpose of pursuing a craft or 'trade'. They draw attention to how Dewey (1933) is critical of such narrow thinking and how he foregrounds the importance of recognizing that the meaning of the word 'vocation' (from the Latin vocātiō) involves a calling to do something well in the world for its own sake and with its own rewards. The setting for this study is particularly interesting since the acceptance of a vocational-academic divide arguably runs wider and deeper in England than in other industrialized economies, in Europe, Asia and Australasia, (Hyland 2017, 2019, Coffield 2008).

An impact of this separation of the vocational and the academic and the elevation of the academic education over vocational education in England, has been that since the early 1980s the development of practice in vocational education is regarded by some as requiring little more than 'training' in a narrow and instrumental set of 'skills' in order to be useful, so that a person can perform a particular job, often

for a single employer. From this perspective, teaching in vocational education is reduced to a kind of mindless, mechanical behaviorism where the job of teachers becomes little more than that of a technician, inserting facts into the minds and conditioning behaviors into the hands and hearts of learners in order for them to be able to perform in accordance with prescribed and easy to measure learning outcomes. As 
lowly technicians, teachers are expected to do what they are told and to make sure that their students do the same.

Young (2007, p. 128) notes how in England the Review of Vocational Qualifications in 1987, signposted a shift away '... from a qualification system based on shared practices and professional judgment, to one based on formally explicit criteria, capable of being defined independently of any specific experience or practice' (original emphasis). Through the work of Raggatt and Williams (1999), he suggests that support for this type of vocational reform was initially tied to the government's determination to break the power of trade unions, which they saw as using trade and craft qualifications to perpetuate restrictive practices.

Young also points out that,

The attempt to 'break with the past' has been a familiar feature of qualification reform, and not only associated with the political Right. Similar frameworks have been introduced in Wales and Scotland strongly supported by the New Left of Centre coalitions leading the Assembly and Parliamentary Executives. (Young 2007, p.129.)

Young locates the roots of this shift, to a political culture which was fueled by the market-driven dogma of consecutive Conservative and New Labour governments. He illustrates how this marked the introduction of an education and training system in England based upon the measurement of narrow outcomes rather than upon more enduring educational concerns which have characterized vocational educational for centuries. The knock-on effect of the perpetuation of a vocational-academic divide in England, coupled with 'top-down' preoccupations with the measurement of educational outcomes, has been to push research in vocational education to the margins of practice in the sector. The upshot of this is that research in the FAVE sector in England has moved into the charge of institutions of Higher Education (HE). Given the above social, cultural and historical backdrop, it is not surprising that the second-rate status of vocational education in England is maintained by class systems and social divisions of labour to this day (Ball, 2018.) The idea of a vocational-academic divide has gained momentum over the years to the extent that practitioners of vocational education are deemed not to be capable of conducting systematic and rigorous research into their own practice. Where sector practitioners have conducted research, it is often regarded to be of a lower standing than research conducted in HE. Research and theory development in the sector have been largely removed from practice and from those actually engaged in practice. So that responsibility for research and theory development in the field of vocational education in England resides almost exclusively in the hands of universities. Responsibility for educational reform, policy implementation and development are also equally distanced from educational practice. What is interesting in all of this is that at no point in this discourse in England, are scholarship, theorizing and research seen as practices in themselves.

\section{METHODOLOGY, METHODS AND THEORETICAL FRAMEWORK}

We do not have to go to knowledge to obtain an exclusive hold on reality. The world as we experience it is the real world. (Dewey, 1929, p.235.)

(R)esearch can only inform practice because it can never replace other knowledge which teachers bring to bear on practical problems; and that even the best research evidence is not available as fixed universal relationships between methods and outcomes but as local context-sensitive patterns which have to be interpreted by practitioners within their particular working environments. [Edwards, 2000, p. 301. (Cited in Coffield 2017, p. 58)] 


\section{DEWEY'S PRAGMATIC EPISTEMOLOGY}

The unifying concept which guides our realization of the pedagogic devices employed in the PRP is Dewey's (1933) pragmatic epistemology. Strictly speaking, Dewey's pragmatic epistemology is not an epistemology in the traditional sense of the word. It does not attempt to provide an answer to the question of how our (immaterial) mind can acquire knowledge of a (material) world outside our mind (Hyland, 2017). Dewey maintains that this mind-body dualism is false. Echoing Socrates (469-399 BC), he cautions against quests which seek to know something 'for certain'. He regards such ventures as misguided on the grounds that they overlook the fallibility of the human condition and the nature of human experience.

Dewey argues that philosophy should not be concerned solely with the problems of philosophers and that philosophical method should be capable of dealing with real world problems. The main significance of Dewey's $(1929,1933)$ pragmatism for educational research, is that it approaches questions about knowledge from a practical angle. Dewey attends to questions of knowledge and the acquisition of knowledge within the framework of a philosophy of action. Dewey's theoretical framework takes action as its most basic category. However, as we point out above, he does not premise his understanding of knowledge upon the existence of a dualism between mind and matter. He takes his point of departure in interactions taking place in nature where nature is understood as a whole of interacting parts with indefinite interactions at its centre. For Dewey, the interactions that are of specific importance are the interactions between the human organism and its environment. Human action he argues is always the interaction between elements of human nature and the natural and social environment.

The interaction or as he describes it transaction of organism and its environment is an active, incremental, adaptive and adjustive process in which the organism attempts to maintain a dynamic balance with its constantly changing environment. Dewey's transactional approach offers an account of the point of contact between the human organism and the world. From Dewey's transactional position, as human beings we are always in touch with our natural and social environment, we are always in some sense 'thrown into the world', we are always doing something in the world. As human beings we can not do something (e.g., breathing, feeling etc.,). However, this does not mean that reality simply reveals itself to us. One of Dewey's key ideas is that reality only reveals itself to us through our actions as well as our experience of those actions and their consequences. In this way, Dewey rejects the mind-world dualism of subject-object from which positivist world views derive. While Dewey accepts that knowledge is a construction, he asserts that knowledge is not a construction of the human mind but a construction that is located in the way in which 'we transact with and respond to changes in our natural and social environment' (Biesta and Burbules, 2003, p. 11). According to Dewey, what is actually universal is not an objective reality but a process of organism-environment transaction where reality emerges through inquiry and in experience.

In our attempts to maintain a dynamic balance with our environment, Dewey claims, we develop patterns of possible action which he calls habits. He argues that we acquire these as we develop a repertoire of possible ways to respond to and transact with our environment through a combination of trial and error and problem solving. He argues that we undergo or suffer the consequences of our actions and try to adjust ourselves accordingly. And so, the cycle repeats itself. Dewey points out that we can escape the immediate consequences of trial and error by performing symbolic operations in the act of thinking, where we can try out different lines of action and imagine their consequences without immediately and directly suffering their consequences. He contends that as we become more adept at considering possible lines of action and their potential consequences, the more precise or "intelligent" our actions can become.

He notes however that it is only when we make a judgment and take action, that we can know whether our chosen line of action was appropriate. For Dewey, his does not imply that each of us constructs only our own individual world. While he accepts that in one sense we all live in a world that is meaningful to us in our own way, he also argues that we live in a world in which we influence and are influenced by others. When we act together in mutual engagement in a shared endeavor he points out, we need to adjust our individual approaches, perspectives and patterns of action in order to make a 
coordinated response possible and, in this process, our individual worlds are transformed. This is not to imply that we become identical but that we share something in common in an intersubjective world we have created in action together.

\section{THE PRACTICE FOCUSED RESEARCH METHODOLOGY OF THE PRP}

In contrast to the 'top-down', 'outside-in' approach to educational research described above, we draw upon the work of Dewey (1933) and Hunt (1987) to make the case that practitioners in the FAVE sector interested in improving educational practice should begin with themselves and value their direct experiences of practice. Hunt explains how, through personal and practical experience, he became dissatisfied with the conventional view that theories developed and verified through research can and should be applied directly to classroom practice. He argues that abstracting theory from practice in this way cuts us off from direct experience thereby removing us from the realities of the practice we are trying to improve.

The 'inside-out' approach underpinning the PRP and its model of educational change and improvement is rooted in experience and grounded in personal and practical knowledge. Hunt (1987) calls for 'inside-out' to come first, 'because among other things, this approach provides a valuable base from which to consider Outside-in information' (p.2). It is important to note that Hunt is not declaring that implicit theories held by practitioners are completely valid or that experienced knowledge is better than all formal theories. He takes the view that identifying implicit theories of practice creates a foundation for determining their validity and value compared with formal theories from 'outside'.

\section{THE UNIVERSITY OF SUNDERLAND-ETF PRP: THE LOGISTICS}

The University of Sunderland-ETF PRP is an extensive national programme of practitioner-research in England which aims to develop understandings of practice-focused educational research, its role in improving educational practice and its potential to contribute to theory. The programme is funded by the Education and Training Foundation (ETF) the national representative body for the FAVE sector in England. The PRP has two pathways, one of which is at a more introductory level the Master of Arts (MA) Level Short Course and the other is a full Master of Philosophy pathway which provides the focus for this study. The PRP aims to open up pragmatic, epistemic spaces in which teachers, education leaders, policy professionals and University research active staff can systematically co-operate in identifying, planning, carrying out and critically evaluating a research investigation designed to explore and improve an aspect of educational practice identified by teachers as being in need of improvement. Depending upon the scale and scope of the research, this includes documenting the investigation and its contributions to knowledge, through the production of a Master of Philosophy thesis of around 60,000 words.

Other research outcomes include the production, presentation and justification of the findings of the research in the form of a research poster and a research presentation at the Foundation's Annual Research Conference in London. These research outputs are providing important sources of evidence of the impact of the PRP. In addition to the above, different forms of quantitative and qualitative data are being collected in terms of research impact and evaluations of residential Research Development Workshops.

\section{RESEARCH DEVELOPMENT WORKSHOPS}

Residential Research Development Workshops are used in the ETF-SUNCETT PRP project to investigate how various stakeholders experience and respond to challenges in conducting, completing and reporting their practice-focused research, including sharing the findings of their research with their colleagues, wider stakeholders, policy professionals and other researchers in the field. The overarching purpose of the PRP is to create epistemic conditions in which teachers, education leaders, policy professionals and university researchers can talk openly about problems in educational practice from a teacher's perspective and in the context of direct experience. PRP practitioner-researchers aim to address 
a number of questions including the question of, if/how educational practice and the development of educational theory can be improved through practice-focused educational research.

The PRP programme of support consists of three Residential Research Development Workshops each of 3-4 days, provided over a ten-month period for practitioner-researchers progressively engaged in Year 1 and Year 2 of a customized Master of Philosophy programme. In addition participants are also supported through a series of regular supervisions and tutorials across the year. Research Development Workshops use 'a variety of stories' of research and practice as well as creative media to help teachers from the sector research to improve an aspect of their practice. Methods used include, stories of educational research, practice and knowledge development; narrative enquiry; multimedia ICT based games and conventional board games; music; film and art. These resources are used throughout the programme to enable and encourage teachers to engage deeply with key ideas and concepts in educational research including epistemological, methodological and educational issues.

In this interim report of our findings we describe how the use of stories of experience, research, practice and knowledge development, together with storytelling devices and narrative inquiry, used in the context of engaging with published educational research texts, are helping teachers to deconstruct the research designs of others to see what we mean by good research in a range of educational situations. Workshops include critical considerations of rigour, originality and significance in educational research. They also involve in-depth discussion of what it means to be critical; how to read between the lines when reading published educational research texts and how to develop individual and collective capacities for research and scholarship. The process of teachers critically evaluating and making sense of epistemological, methodological and educational issues for themselves in the contexts of their own practice resides at the core of the PRP programme.

The interim analysis draws upon data from a cohort of 27 practitioner-researchers engaged in the customized Master of Philosophy pathway of the PRP over a two-year period. Our intention is to capture critical incidents and important pedagogical moments in the development of research capacity including raised levels of awareness of epistemological, methodological issues in educational research as evidenced in the work of practitioner-researchers involved in the study. For the analysis presented here we use data collected between November 2018 and April 2019. These data sets include, 11 days of direct engagement in/observations of teaching and learning across four of the seven Residential Research Development Workshops, 162 supervision tutorials, evaluations of four Residential Research Development Workshops, ongoing analysis of 27 Research Posters in progress, 27 Impact Grids and 27 Abstracts in preparation for presentation at the ETF Annual Research Conference in July 2019 which takes place at the end of the first year of fieldwork on the project. Later this year, data sets will also include analysis of MPhil chapters and theses.

To sum up, the study employs a number of research methods. These include the analysis of a variety of research outputs produced by practitioner-researchers (including scholarly research posters, MPhil theses, case studies, critical incidents and other reported measures of impact). These data sets are being supplemented by data from evaluations of Research Development Workshops.

\section{REALISING THE PRP IN PRACTICE: SOME ILLUSTRATIVE EXAMPLES}

Earlier in this paper, we argue that approaches to educational improvement which aim to build the capacities of practitioners from the 'inside-out' and from the 'bottom-up' can enable them to conduct systematic and rigorous research into the improvement of their own educational practice. In this section we offer more detailed insights into an alternative way of investing public funds in educational improvement. We suggest that this pragmatic approach to educational evaluation and improvement is more likely to yield returns in terms of actual educational gains than are possible under the current system.

The aspects of the study presented here, bring to light examples of how research methodologies and methods, theory and research are contextualized, re-contextualized and realized in practice in the PRP. We describe here how our own experiences of practice combined with those of others in the form of 
narrative accounts of experience inform the design of the PRP. We draw attention to how factors influencing the development of the pedagogic devices employed in the PRP began in our own encounters with and experiences of problems in practical educational settings. We explain how we share these personal and practical experiences as stories with practitioners engaged in the PRP. We also explain how we use our own stories of research and practice and those of others to make complex ideas and concepts accessible and useful to practitioner-researchers in the sector.

\section{EXAMPLE FOR MPHIL YEAR 1TALKING ABOUT WHAT'S REALLY HAPPENING: 'FELT DIFFICULTY'}

Following Dewey (1933), the motivation for this study including the work which led to the subsequent development of the PRP is essentially pragmatic. Pragmatic in the sense that the initial 'felt difficulty' (or disturbance) which first troubled us and led us to begin to develop the PRP emerged from indeterminate problems we encountered in our own practice regarding concepts, ideas and theories about, 'reflective practice'; 'excellence in education'; 'educational improvement from the top-down'; and 'educational evaluation from outside-in'.

These disturbances came to light for each of us at different times and in different ways as we variously tried to put ideas from research and theory developed by others into practice in the contexts of our own work. What they have in common is that in all of these situations, each of us was uncertain about how to respond to the indeterminate circumstances in which we found ourselves. We did not know what to do next.

\section{EXAMPLE FROM MPHIL YEAR 1}

We report elsewhere (Gregson and Spedding, 2018) how personal and practical experiences helped us to see first-hand how the relationship between educational research and educational practice cannot be reduced to the simple application in practice of research conducted by others. This example illustrates how our experiences informed the design of MPhil Year 1, Research Development Workshop 1 in relation to helping practitioner-researchers to talk about what is actually happening in practice in order to begin the research process and to try to identify the 'Research Problem'.

\section{DEWEY'S THEORY OF INQUIRY: SEEING THE PROBLEM THROUGH THE PRP}

Dewey's theory of inquiry does not rely on an objectivistic understanding of what problems are, problems are not regarded as simply being "there", but as emerging from an indeterminate situation where something is identified as being problematic and therefore in need of inquiry because we do not yet know what the problem is. The process of inquiry into the transformation of the situation is purposive, controlled and directed Dewey argues, through the cooperation of reflection (or careful thinking) and actions which aim to transform the situation.

In the PRP MPhil Year 1, the process of inquiry begins when we ask practitioner-researchers to talk about what is actually happening in practice. Finding out what is problematic about an indeterminate or uncertain situation is a crucial moment in the process of inquiry. Echoing Dunne $(1993,2005)$ we note how in developing the PRP we revisit and share how we encountered these troubling aspects of our own educational practice before we knew what the problem was; before we knew what to do about the problem; before we knew what it would take to address the problem. Through our stories we share how each of the felt difficulties we encountered was present before we came to see what each called for. Each of the felt difficulties we encountered was present before we knew what it was and before came to see that they could not adequately be addressed without engaging in critical consideration (in all three cases) of the epistemic relationship between educational practice, theory and research. 
In turn our stories tell how these experiences brought into sharp focus, the limiting assumptions and inherent tensions in the divisive relationships between practice, theory and research as they are framed in technical-rational, 'top-down' and 'outside-in' approaches to educational improvement.

Our stories explain how we arrived at a point where we could assert that, far from teachers being the passive consumers of knowledge produced by others in the form of 'blueprints' or 'recipes' for teachers for good practice, our own experiences reveal how practice can become the arena in which theory and research are tested. Our stories explain how closer and more careful examination of our experiences foregrounded how teachers can be creators of new knowledge as well as potential generators of and contributors to educational theory.

Our stories are mindful of and connect to the work of Eraut (2004), Kemmis (1995) and Carr (1995). Through our stories and theirs we provide examples of how the new learning involved in putting an idea or concept or theory into practice is a form of inquiry and therefore an important and legitimate form of educational research. In turn, we explain how these experiences came to influence the epistemology underpinning the PRP.

\section{EXAMPLE FROM MPHIL YEAR 1: EMBODIED PRAGMATISM RESEARCH DEVELOPMENT WORKSHOPS 1-3}

Although we do not 'teach' this explicitly in MPhil Year 1, our engagement with the work of Dewey as described above, has developed the PRP into a kind of 'embodied pragmatism' in which we work alongside practitioner-researchers to incrementally understand the nature of the educational problem in question and the ways in which issues and problems encountered in practice might be addressed. MPhil Year 1 Residential Development Workshops 1-3 focus upon beginning the process of inquiry by, talking about, the 'felt difficulty'; what is really happening in practice; what the nature of the problem might be: how we can learn from the experiences and stories of others, who have encountered these 'felt difficulties' before, both face-to-face and in published literature; the lines of action they have taken and the consequences of these actions in practice.

\section{EXAMPLE FROM MPHIL YEAR 1: THE IMPORTANCE OF STORIES OF RESEARCH IN PRACTICE IN THE PRP}

Gregory (1973) reminds us that as human beings we are all shaped by stories. We are shaped by the stories we hear and the stories we tell. Stories give us a lens through which we can understand the workings of the world. A story about one person's experience can offer us insights into our own lives, other ways of seeing the world, other ways of doing things. Stories can help us to understand things that are difficult to grasp in other ways. Stories can help us to share 'felt difficulties'. Stories can also help us to address them.

\section{LINKING TO LITERATURE AND LEARNING FROM STORIES OF EXPERIENCES AND THE RESEARCH OF OTHERS}

We have discussed above how published philosophical, methodological other works inform pedagogical interventions in the PRP. The work of Dewey (1933) and Hunt (1987) are used to draw attention to the importance of taking experience seriously and to explain why we and the practitionersresearchers engaged in the PRP 'begin with ourselves'. The work of Gregory (1973) is used regarding the power of stories to shape thinking and the development of character. The work of Dunne $(1993,2005)$ is drawn upon to highlight the shortcomings of 'top-down', 'outside-in', technical-rational approaches to education and educational improvement in practice. The same works also contribute to discussion of the approach informing the PRP regarding the nature of a practice and how a practice develops. The works of Eraut (2004), Kemmis (1995), Carr (1995), Fielding et al (2005) Sennett (2008) Hyland (2017, 2019) offer perceptive insights (some through stories) into the processes and the new learning involved in 
putting an idea into practice and then refining and improving it in context. Fielding et. al. (2005, ) draw attention to how the fundamental challenge for policy makers is the question of how to 'scale up good work' that has been developed through pump-primed funding to areas where it is not funded without losing the dynamism and authenticity of the original (p.2). These authors challenge simplistic notions of 'transfer' based on the assumption that good practice can be identified and transferred simply by telling teachers about the good practices of others. Instead they suggest a number of factors which they found to be capable of positively influencing the transfer of good practice. These include an approach to educational evaluation and improvement which they describe as Joint Practice Development (JPD). This involves the creation of conditions in which teachers can work together to jointly improve their practice in situations of co-operation, collaboration and trust and in circumstances in which the realities and the time it takes to change and improve practice are taken seriously by both policy professionals and education leaders. The PRP builds upon and extends the work of Fielding et. al. (2005) by introducing a number of pedagogic devices which foreground direct experience, collaboration, cooperation and sharing experiences of educational research and improvement through story. This is not to imply that the pedagogic devices underpinning the PRP, direct experience, story and the development of practice operate in a discrete way. They do not. They are intimately connected in a dynamic interchange between knowledge and action. This emerges in the process and progress of the PRP in situations where statements about the external world constantly, subjectively and inter-subjectively 'face the tribunal of sense experience' (Biesta and Burbules, 2003, p.7). From this perspective, observation in the contexts of research never gives us knowledge but only becomes meaningful through interpretation, as we bring a whole body of assumptions and theory into dialogic interplay as we work to make sense of experience.

\section{EXAMPLE FROM MPHIL YEAR 1: BEGINNING WITH OURSELVES}

Hunt uses his own experience of becoming a psychologist to help us to see how the axioms of the scientific method and its concerns with the rigour and precision of the experimental method led him to investigate into how jazz musicians, with their improvised solos are able to communicate specific states of emotion to the listener. He describes his own initial research exercise as pretentious. Likewise, he is equally critical of his own reporting of its rather ambiguous findings, describing it as being couched, 'in an almost incomprehensible, highly qualified jargon - which concluded with a call for more research' (pp.11-.12). Hunt uses this experience to draw attention to the dubious value of 'outside-in' applications of 'scientific method' to matters of human experience. He notes that the quality of human experience is a neglected aspect of educational research and that the starting point in the change process is personal and practical knowledge rather than theoretical knowledge. In sum, he reminds us of the importance of beginning with experience, 'beginning with ourselves'.

\section{OUR STORIES}

For Daniel, the educational problem he encountered was connected to finding ways of encouraging reluctant learners to write in the face of difficulties he experienced with the implementation of esteemed and widely promoted phonics schemes used in the teaching and learning of English in schools in England. Daniel's account of how he tried to address this problem in practice became the focus of his dissertation and a subsequent peer-reviewed publication.

The educational problem which Maggie encountered was first related to difficulties she experienced as a policy professional and external evaluator in vocational education contexts. Her work required her to make judgements about the practices of others and to offer suggestions about how these practices could be improved. The difficulties and dilemmas she found in trying to make this idea work in practice, led her to undertake a Master of Arts Degree in order to explore these issues further. Secondly, her own inability to use a Reflective Diary to develop her practice which she was required to complete as an integral aspect of her own professional development, coupled with similar difficulties experienced later by her students 
as they also attempted to complete reflective diaries, led her to question dualisms in notions of reflective practice which she then explored as part of her Doctoral Thesis.

Trish's experiences of evaluating a programme of professional development for teachers in primary schools in parts of rural England led her to recognize the value and the limitations of the use of mixed methods in educational research as well as providing her with first-hand practical experiences of more illuminative and democratic approaches to educational evaluation.

We share these personal and practical experiences with practitioner-researchers engaged in the PRP in some detail. These include accounts of how our experiences eventually led us to engage in a co-operative search with policy professionals in ETF and practitioner-researchers from across England to explore what an epistemic alternative to current approaches to educational research, evaluation and improvement based upon pragmatic rather than technical-rational epistemic perspectives might look like. We explain that this is the ethos of PRP.

We make it clear that we did not begin with an understanding of what the conditions for an alternative approach to educational evaluation and improvement might be. We describe how these have come to light and are still coming to light in the course of this study. We ask practitioner-researchers to note how once again our own experiences of educational practice and educational research as we have described above helped us to see that the relationship between educational research and educational practice cannot be reduced to the simple application of knowledge gained from research conducted by others. Similarly, we explain our own work in the fields of, literacy development, educational evaluation and improvement and studies of reflective practice, originated in problems we encountered in trying to put theories and ideas from the educational research of others into practice.

\section{EXAMPLE FROM MPHIL YEAR 1: ENTREE AND EXIT}

We explain in some detail above, how in Year 1 of the MPhil pathway of the PRP we begin by sharing our own stories of our experiences of research in practice as well as the stories of other researchers who have come to influence our thinking and our work. This is done to make the point that it is important in research to begin with ourselves, to take experiences of practice seriously and to help practitioner-researchers to appreciate that the education problem may not be as simple as it might first appear and the solution may not be as obvious as they think! We then invite practitioner-researchers to talk about what is actually happening in their practice and to share their own experiences of practice with us and with each other to try to develop a deeper understanding of the educational problem. We also point to the importance of looking to the work of other researchers who have encountered problems in research and practice before us and the positions they have arrived at to date. This is done in collaboration and open discussion so that we can gain a collective sense of the research experiences and interests of the whole group and identify where there may be pockets of shared interest and opportunities for future mutual endeavor and support.

This sharing of stories of research in practice beyond our own experiences of practice and those of practitioner-researchers is done in a number of ways. We begin by sharing examples of published works by prominent researchers which are virtually incomprehensible because of the imprecision, ambiguity and complexity of the language used and the effects of this upon the reader.

Next, we bring the experiences of research conducted by equally prominent but more accessible researchers who bring research to life in ways which extend an invitation to practitioner-research to be 'part of the action', an invitation to participate in the research, to look at what they did and to see what they saw (Peshkin, 1985).

For example, the work of Coffield (1983) in Entree and Exit, presents a rich and vivid account of the early career research experiences of someone who is now an internationally esteemed educational researcher. Coffield writes about a research study which goes badly wrong to the extent that he has to run away from the site of the research only to be chased along the street by the research population. Even in these dire circumstances Coffield has the courage and a healthy commitment to the principles of good research in education to be able to write up his research in a systematic, rigorous, robust and authentic 
way. Coffield brings the rigour and significance of his research to the fore by employing a balance of research methods appropriate to the work that researchers in the field of education have to do in order to report the research experience.

The main purpose of sharing this publication with practitioner-researchers engaged in the PRP is to help them to see that research in the sector does not always proceed in predictable ways and that even when things do not go as well as expected a good researcher will not try to disguise shortcomings in their research but will report them fully and accurately when the research in published. Another reason for sharing this publication with PRP participants is to demonstrate how case study can tell the story of the research in ways which ignite the interest of the reader which other less personal methods of reporting research would struggle to do. We also invite practitioner-researchers to work together to deconstruct the methods and methodology employed in Coffield's (1983) study. These include an introduction explaining the socio-economic and political factors in play in the context of the research, followed by a rich and engaging case study and discussion. At the same time, we introduce practitioner-researchers to other basic publications in the field of research methods which offer more conventional introductions to planning research and basic research techniques.

To drive the point home that experiences of research seldom work out exactly as planned, we use a number of clips from the popular movies, boxsets, YouTube and social media to draw attention to the challenges and realities of conducting educational research. These include a variety of stories from film, art, music, television, including, runaway golf carts and military parades etc. We use these to highlight important messages about the realities of the conduct of educational research and approaches to educational improvement in practice.

An example developed specifically for the PRP is the use of The Good Research Game, a board game, specifically designed to bring home some key principles in conducting educational research in a meaningful but lighthearted way.

\section{EXAMPLE FROM MPHIL YEAR 1: A LIFE IN RESEARCH}

In Year 1 we also introduce some of Coffield's more recent works $(2008,2009,2010,2014,2017)$. These are brought to bear in order to help practitioner-researchers to see the trajectory of the research career of a single researcher. These publications are also offered as additional opportunities to not only deconstruct the methodology and methods 'in action' as they used a range of research publications, but also to encourage practitioners to examine how the author writes in a scholarly way which is both accessible to a range of audiences while at the same time being acceptable to the academic community's expectations of high standards of argument construction, citation and referencing.

In Year 1 of the MPhil we employ the work of Hyland $(2017,2019)$ to open up discussion of the existence or otherwise of a vocational-academic divide. The purpose of exploring these publications with practitioner-researchers is to help them to recognize that epistemologies are culturally, historically, socially and politically constructed and that practitioner-researchers in vocational education have a right and indeed a moral obligation to research and improve their own practice rather than to accept that their practice, their research or their ability to theorize is second rate or in any way of less importance or value than their counterparts in HE. In addition, Professor Hyland attends a Year 1 Research Development Workshop to share his story of research in person.

The work of Sennett (2008) also plays an important part in the MPhil Year 1, in inviting considerations of his richly described stories and accounts of the nature of skill and the processes and stages involved in the development of practice.

\section{EXAMPLE FROM MPHIL YEAR 2: METHODOLOGY REVISITED}

We have described above how in Year 1, the focus of the PRP is upon, recognizing the need for valuing experience; the importance of beginning with ourselves; being able to talk about what is really happening including 'felt difficulty'; beginning a process of inquiry directed at understanding the nature 
of the problem; developing research and scholarship through experience and story; the legitimacy of and unique contribution of practitioner-research; challenging divisions between theory, research and practice; critically questioning the vocational-academic divide. Basic debates in educational research including methodological and methods issues are also introduced. Engagement with the ideas of Dewey and others are supported by pedagogical interventions informing the PRP. Some of these are described in detail above.

In Year 2 Dewey's pragmatic epistemology continues to inform the ethos and pedagogical interventions employed in the PRP. At this stage however, philosophical concepts of epistemology and ontology have been introduced but not explored in depth. A this point the stories/biographies of Socrates, Plato and Aristotle and others, these are considered in greater depth as practitioner researchers draft and refine the Research Methods chapter of their thesis and to reinforce the idea that positivist versus constructivist world views do not come from 'the gods' but from the ideas of those before us who have tried to make sense of truth and reality .

The following example from the work of Dunne is employed a pedagogical intervention, offered here for illustrative purposes.

\section{REVISITING TECHNICAL-RATIONAL, TOP-DOWN APPROACHES TO EDUCATION: BLOOM'S TAXONOMY AND THE WORK OF DUNNE (1993)}

It is not easy for those engaged in the PRP to grasp why something as intuitively appealing as just telling practitioners about somebody else's good practice does not work. The nature of a practice and the pragmatic processes through which a practice changes and improves are complex. On the other hand, notions of the validity of 'cascade', 'beacons of excellence', 'advanced practitioners', 'champions' or other technical-rational slogans and approaches to educational improvement are deeply-entrenched and consequently hard to shift. That is why in addition to sharing our own stories of experiences of the difficulties of putting ideas from theory and research into practice, we encourage participants in the PRP to share their stories of practice with us and with each other. The work of Dunne (1993, pp.1-27) is introduced in the PRP to tell a story of the background to and implementation of Bloom et al's (1956) Taxonomy, a piece of research with which every teacher in England is familiar and which many of them use every day. Dunne shares his story with us. He tells us of his encounter with the technical-rational introduction of behavioural objectives to education. Behavioural objectives which were supposed to revolutionize education by making it more 'scientific'. He talks about the perceived practical problem of there being 'a lack of science' in the discipline of Education that 'needed to be addressed'.

Dunne recounts his experience with Bloom's Behavioral Objectives Model. He explains that the aim of the model was to strip back planning and the method of teaching his students to a list of 'behavioural objectives' or 'learning outcomes'. He describes how the model turned on the success of the teacher being able to demonstrate on a surface level that the student had understood what they had been shown or told and therefore achieved the objective and how this formulaic and instrumental system was rolled out across his college. He describes how Bloom's Behavioral Objectives Model was hailed as the 'Royal road to efficiency in teaching'. He goes on to point out how this model was designed against the backdrop of the 'New Science of Education' which was supposed to bring clarity and remove some of the old rhetoric and practical know-how often associated with teaching. Through his story Dunne reveals how remotely designed theories and 'top down' approaches to educational research can be damaging to the practice of education and points out that the popular technical-rational, 'one size fits all' approach to educational research, improvement and reform while intuitively appealing, rarely if ever hits home.

The grip of Bloom's Behavioral Objectives Model is still a common problem today and practitionerresearchers we see who interact with on a regular basis often struggle with the tensions of its intuitive appeal alongside its dulling technicality. Paradoxically this is often compounded by the zealousness of its imposition by management from the top-down'. 
PRP practitioner-researchers tell many other similar tales to those of Dunne in their accounts of what is actually happening in practice, including models and policies designed to enhance, streamline, or boost efficiency of their colleges and their teaching.

Evidence from the PRP suggests that these practical stories and experiences are being undervalued and diminished by managers in favour of external, reforms imposed from the top-down. Dunne's argument that the practical wisdom of teachers in their field should not be ignored or belittled is a powerful one and one that the PRP aims to echo. To frame some of the pedagogical interventions in the PRP around his argument is a good starting point.

\section{WORK IN PROGRESS: DEVELOPING RESEARCH CAPACITY AND SCHOLARSHIP IN THE PRP}

We are currently in the process of analyzing and presenting data generated in the study in relation to practitioner-researchers' examples of developing research capacity and scholarship. These findings will be reported more fully in a forthcoming paper in late 2019 or early 2020.

Our work on the PRP in relation to the development of research capacity is guided by Dewey (1993) where he points out that the way we know something reveals itself to us initially on the level of action and only later in symbolic forms like language. In the context of the PRP, it is important to note, that the development of a language to think, talk and write in, in careful, considered and critical ways about direct experience and research, plays an important role in helping PRP practitioner-researchers to face the, 'tribunal of sense experience' in practice. For this reason, the incremental approach adopted to the development of the conventions of research including, talking about what is really happening in practice and taking time to identify and understand the research problem in Year 1 is purposive. Equally purposive is the PRP's positioning of in-depth consideration of research methodology in MPhil Year 2 rather than Year 1.In Year 1 the main emphasis in the PRP focuses upon identifying the educational problem in practice and in beginning to engage with the thinking and writing of others who have encountered this problem before us. The study of epistemology, ontology and methodology are left to Year 2 on the grounds that ideas of reality and truth should also be allowed to emerge not only from the experience of respected philosophers but also those of PRP practitioners themselves.

The development of research capacity and scholarship in the PRP is therefore pragmatic and grounded in, regular shared experience, co-operation, mutual engagement in a shared endeavor, critical dialogue as well as in a range of forms of written communication, problem-finding, problem-solving.

\section{SUMMARY AND CONCLUSION}

Through the work of Dewey (1929, 1933), Biesta and Burbules (2003), Kemmis (1995), Carr (1995) and the stories of Gregory (1973), Coffield (1983, 2017), Dunne (1993), Hunt (1987) and Sennett (2008), among others, we have shared our experiences and understandings of developing and supporting, practitioner-research in the PRP. We have made the case that educational research needs to be conducted by educational practitioners in the settings of the educational practice that constitute the sites of their work.

We suggest that the pragmatic approach to educational improvement underpinning the PRP may offer a corrective ( or at least a complementary approach) to some of the shortcomings of 'top-down', 'outsidein', neoliberal and positivist metanarratives in the field of educational evaluation. We have highlighted the importance of engaging teachers in more democratic and cooperative forms of educational research related to the improvement of their practice. We have described critical moments in and provide examples of pedagogical interventions in the development of research capacity and scholarship in the PRP. The theoretical framework underpinning the PRP is explained with reference to a number of seminal texts. Through the work of Dewey (1933) and Hunt (1987), we have foregrounded the important role of experience in the improvement of educational practice. Through the work of Gregory (1973), we have pointed to the power of stories to make complex ideas accessible, shape thinking and contribute to the 
development of character and good judgement in practice. We have brought to life, the shortcomings of 'top-down', 'outside-in', approaches to the improvement of educational practice, premised on technicalrational world views with reference to the work of Hunt (1987) Dunne (1993, 2005), Sennett (2008) and Coffield, 2017) .

The PRP aims to help tackle research projects that are not only relevant to practitioner's areas of expertise and have an impact on their practice but also have the potential to inspire other practitioners to research their own practice and tell their own stories of research and inquiry. Emerging evidence indicates that a significant number of practitioners in the PRP subsequently provide practical role models for their colleagues which in turn enables them to engage in practitioner research. This points to a potential sustainability in PRP's approach to the development of educational improvement, research and scholarship.

Evidence from our interim analysis of the PRP indicates that participants in the programme are encouraged to develop their thinking by critically engaging with and deconstructing key texts in educational research. Emerging evidence suggests that this experience gives them the basic tools they need to research their own practice in systematic and rigorous ways, informed by both theory and research in situations where practice is advanced in the light of empirical evidence.

We conclude that stories of experience and research methods can and should be told by those doing and living the research and not only reserved for the attentions of researchers removed from the realities and challenges of educational practice in the FAVE sector.

Contributions from the above works are helping us to frame the development of what we believe is a coherent alternative model of education improvement. This model is informed by theory and research from the disciplines of Education, Philosophy and Sociology. We use these contributions to make the case that 'inside-out' and 'bottom- up' approaches to educational evaluation and improvement are at least worthy of consideration as an alternative or a least a complementary approach to 'top down' and 'outsidein' models of educational change.

The current system of educational evaluation and improvement in England, conducted through Ofsted inspections, has some merits and performs some functions well. However its methods rely, in the main, upon a 'top-down' and 'outside-in' model of educational improvement based upon what is largely a technical-rational world view which overlooks the nature of a practice and the processes through which a practice improves in context.

\section{REFERENCES}

Arnove R. (2002). Comparative and International Education Society' (CIES) Presidential Address, Facing the Twenty-First Century: Challenges and Contributions. Comparative Education Review, 5(34), 477-503.

Ball, S. (2008). Education Debate. Bristol: The Policy Press.

Ball, S. (2018). The tragedy of state education in England: Reluctance, compromise and muddle - a system in disarray. Journal of the British Academy, 6, 207-238.

Biesta, J., \& Burbules, N. (2003). Pragmatism and Educational Research. Maryland: Rowman \& Littlefield Publishers, Inc.

Bloom, B.S., Engelhart, E.J., Hill, W.H., \& Krathwohl, D.R. (1956). The Classification of Educational Goals, Handbook 1: Cognitive Domain. New York: McKay,

Carr, W. (1995) For Education: Towards Critical Educational Inquiry. Buckingham: Open University Press.

Coffield, F., \& Borrill, C. (1983). Entree and Exit. The Sociological Review, 31(3), 520-545.

Coffield, F. (2008). Just Suppose Teaching and Learning Became the First Priority. London: Learning and Skills Network (LSN).

Coffield, F. (2009). All You Ever wanted to Know About Learning and Teaching but were too Cool to Ask. London: Learning and Skills Network (LSN). 
Coffield, F. (2010). Yes, but what has Semmelweis to do with my Professional Development as a Tutor? London: Learning and Skills Network (LSN).

Coffield, F., Costa, C., Miller, W., \& Webber. J. (2014). Beyond Bulimic Learning: Improving teaching in further education. London: Institute of Education Press.

Coffield, F. (2017). Will the Leopard Change its Spots? A new model of inspection for OFSTED. London: UCL IOE Press.

Dewey, J. (1929). The Quest for Certainty. In Boydston, J., A., Poulos, K., (Eds.) (1978) Checklist of Writings about John Dewey. Second Edition. Carbondale: Illinois South University Press.

Dewey, J. (1933). How We Think: A Restatement of the Relation of Reflective Thinking to the Educative Process. Boston, MA: D.C. Heath \& Co Publishers.

Dunne, J. (1993). Back to the rough ground. Indiana: University of Notre Dame Press.

Dunne, J. (2005). What's the good of education? In W. Carr (ed) The Routledge Falmer Reader in Philosophy of Education, pp. 145-160, Abingdon, Oxon: Routledge

Edwards, T. (2000). p.58 cited in Coffield, F. (2017) Will the Leopard Change its Spots? A new model of inspection for OFSTED. London: UCL IOE Press.

Eisner, E. (1993). Forms of Understanding and the Future of Educational Research. Educational Researcher, 22(7), 5 - 11.

Eraut, M. (2004). Transfer of Knowledge Between Education and Workplace Settings. In Rainbird, H., Fuller, A, and Munro, A, (Eds.) Workplace Learning in Context. London: Routledge. pp. 201221.

Fielding, M., \& Thorpe, J., et al. (2000). Factors Influencing the Transfer of Good Practice. Sussex: Department for Education.

Gardner, J., Holmes, B., \& Leitch, R (2008). Where there is smoke, there is (the potential for) fire: soft indicators of research and policy impact. Cambridge Journal of Education, 38(1), 89 - 104.

Gregory, M. (1973). Shaped by Stories: The Ethical Power of Narratives. University of Indiana: University of Notre Dame Press.

Gregson, M., \& Nixon, L. (2011). Unlocking the potential of Skills for Life (SfL) tutors and learners: a critical evaluation of the implementation of SfL policy in England. Teaching in Lifelong Learning Journal, 3, 52-66. 10.5920/till.2011.3152.

Gregson, M., \& Spedding, T. (2018). Learning Together: Evaluating and improving Further Adult and Vocational Education through practice-focused research'. In Nägele, C., \& Stalder, B. E. (Eds.) (2018). Trends in vocational education and training research. Proceedings of the European Conference on Educational Research (ECER), Vocational Education and Training Network VETNET). (pp.157-164). https://doi.org/10.5281/zenodo.1319661

Hunt, D. (1987). Beginning with Ourselves. Cambridge MA: Brookline Books.

Hyland, T. (2017). Craft Working and the "Hard Problem" of Vocational Education and Training. Open Journal of Social Sciences, 5, 304-325. Retrieved from https://bolton.academia.edu/TerryHyland

Hyland, T. (2019). Embodied Learning in Vocational Education and Training. Journal of Vocational Education and Training, 71(1).

Kemmis, S. (1995). In Carr, W. (1995) For Education: Towards Critical Educational Inquiry. Buckingham: Open University Press.

Peshkin, A. (1985). Virtuous subjectivity: in the participant observer's eyes. In D. Berg, D\&K Smith (eds) Exploring clinical methods of social research. pp. 267- 281, Beverly Hills: Sage.

Raggatt, P., \& Williams, S. (1999). Governments, Markets and Vocational Qualifications: an Anatomy of Policy' cited in Young, M.F. D. (2007) Bringing Knowledge Back In. Abingdon. Oxon: Routledge.

Sarason, S. (1990). The Predictable Failure of Educational Reform. San Francisco: Jossey-Bass.

Sennett, R. (2008). The Craftsman. New York: Penguin.

Young, M. F. D. (2007). Bringing Knowledge Back In. Abingdon Oxon: Routledge.

52 Journal of Management Policy and Practice Vol. 20(3) 2019 